\title{
Vlasova I.V. \\ The need for the formation of intercultural communication skills among students of technical specialties in a non-linguistic university
}

Samara State Technical University

(Russia, Samara)

doi: $10.18411 / \mathrm{lj}-10-2019-151$

idsp: ljournal-10-2019-151

\section{Abstract}

The article considers the need for the formation of sociocultural competence in foreign language teaching in a multicultural society and the formation of intercultural communication skills among students of technical specialties in a non-linguistic university. The authors suggest the stages of sociocultural competence formation: namely, teaching of non-verbal communication: (kinesics, proxemics, chronemics) and awareness of the other cultures. Special attention is given to the issue of cultural stereotypes and attitudes towards them.

Key words: university students, foreign language, intercultural communication, multicultural society, general cultural competencies, stereotypes.

As a result of socio-economic transformations in Russia, highly qualified human capital becomes the main resource - specialists with such qualities as mobility, competitiveness, the ability to apply their knowledge and skills in constantly changing conditions, the ability to self-education, sociability, creativity, independence, responsibility and determination.

The higher education system is currently facing the important task of creating competencies, which are a system of universal knowledge, skills, experience of independent activity and personal responsibility of students.

In this regard, the federal state educational standards of higher education pay great attention to the formation of professional and general cultural competencies among students. This fundamentally new approach to teaching focuses on the formation of students' ability to apply knowledge, skills and personal qualities for successful professional activities in a specific subject area, which should contribute to the social mobility of graduates and competitiveness.

A number of scientific publications have shown that in the process of mastering a foreign language, students can develop along with professional competencies, intercultural communicative competencies $[1,2]$ since a foreign language is used as a means of obtaining foreign scientific, technical, cultural and socio-economic information, as a means of intercultural and foreign language communications with foreign scientists and specialists, with workers in science and culture, as a means of using global Internet in their respective domains of knowledge. [3]

The formation of general cultural competencies in the process of teaching students a foreign language can be carried out only in the process of intercultural communication, when communication in a foreign language occurs, taking into account the difference in cultures and stereotypes of thinking.

In the context of the current situation, one of the problems that impede communication between representatives of different cultural traditions is the low level of intercultural competence. To raise the level to a higher level when teaching young specialists at a university, it is necessary to use techniques in the educational process that promote students to develop an interest in the culture of the language being studied, knowledge and a correct understanding of the behavior of representatives of other ethnic groups. 
In our opinion, when studying a foreign language, of course, it is important to get acquainted with the cultural characteristics of a country or countries where the language being studied is native, including ethnic stereotypes of these countries.

The acquisition of intercultural communicative competence, which is a functional ability to understand the views and opinions of representatives of another culture, to adjust one's behavior, to overcome conflicts in the communication process, is becoming in demand for a modern specialist. It creates the basis for professional mobility, preparation for rapidly changing living conditions, increases the possibilities of professional self-realization on the basis of communicativeness and tolerance. [4].

Intercultural communicative competence is associated with how a person perceives a partner for one or another type of communication, how he positions himself. Based on this, he will look for different ways to achieve his goals. Here, knowledge of stereotypes and the correct attitude to them will help him. If you predict the behavior of a partner in advance, then you can adequately assess the situation and choose the correct line of your behavior.

So, for the formation of the general cultural competencies of students in a nonlinguistic university, as part of teaching a foreign language, a mandatory acquaintance with the features of foreign cultural communication is offered.

Undoubtedly, entering into intercultural contacts of any kind, people interact with representatives of other cultures, which can differ significantly from each other. Differences in languages, behaviors, clothing, and attitudes toward the work being done often make these contacts difficult. This leads to the conclusion that effective intercultural communication does not arise on its own, it needs to be learned.

It should be noted that intercultural education is aimed at developing students' ability to intercultural communication and helps students to become aware of their belonging to a particular ethnic group, as well as familiarize themselves with the cultural characteristics of representatives of another culture.

Consider the main types of non-verbal communication, which also affect the process of mutual understanding of representatives of different cultures.

Kinesika is a combination of gestures, gestures and postures used to complement expressive means of communication. Gestures used should be understood clearly, because if the gestures are misinterpreted, unpleasant circumstances can arise. For example, a simple gesture connecting the index finger and thumb means "OK" for the American, "zero" for the Frenchman, "money" for the Japanese, and "I will kill you" for the resident of Tunisia.

Tactile behavior. A comparative comparison of the behavior of representatives of different cultures made it possible to establish that when communicating, people of different cultures use various types of touches to their interlocutors: handshakes, kisses, stroking, patting, hugs, etc. [5].

Proxemics is the use of spatial relationships in communication. This term was introduced by the American psychologist E. Hall to analyze the patterns of the spatial organization of communication, as well as the influence of territories, distances and distances between people on the nature of interpersonal communication. Each person for his normal existence believes that a certain amount of space around him is his own and considers the violation of this space as an invasion of the inner world, as an unfriendly act. [6].

Americans, for example, during communication prefer to be close to the interlocutor, can impulsively hug, pat on the shoulder, shake hands, emotionally involving the interlocutor in the conversation. While representatives of Asia maintain a certain distance, personal space, between themselves and their interlocutor, and often perceive excessive approach, emotional touch and gestures as rudeness and disrespect.

Chronemics - this type involves the use of time in non-verbal communication. During business negotiations, Asians need time to get to know the person they are dealing with. Asians will start negotiations only after a long polite conversation on common topics, stating 
the need to think before making a responsible decision. Americans, on the other hand, value a more direct approach to negotiations and see conversation as a waste of time.

Nowadays, when international contacts are becoming more widespread and intense, special attention should be paid to such a concept as a stereotype. The clash of stereotypes characteristic of different cultures can create difficulties in communication and lead to a misunderstanding of the culture of another people. What is a stereotype? Each nation has its own ideas about itself, about the world, about people and representatives of another culture. Thus certain stereotypes take shape in society - both regarding themselves, regarding behavior and traditions within their cultural space and regarding representatives of a different linguistic and cultural space. For a long time there has been a debate about the definition of the concept of "stereotype". The term "stereotype" (Greek stereos - solid, typos - imprint) was introduced into the scientific circulation by the American sociologist W. Lippman. In the book "Public Opinion", published in 1922, Lippman made an attempt to determine the place and role of stereotypes in the system of public opinion. By stereotype, he understood a special form of perception of the world around us that exerts a certain influence on our feelings before this effect reaches our consciousness. [7]. A person, perceiving the world in accordance with the ideas, relationships and values that prevail in his native culture, behaves as is customary in his environment. Therefore, people's ideas about the world are always relative and diverse; they depend on the culture in which a person was born and raised.

"The system of stereotypes," wrote Lippman, "is perhaps the core in our personal tradition, it protects our place in society, ... and also saves time in our busy lives and helps us to escape from confusing attempts to see the world sustainable and embrace its entirety. "[7].

The behavior of each person is individual and diverse, but it can be asserted with confidence that human behavior in any society is typified, that is, it obeys the norms developed in this society. Stereotypes exist in any society, but it is important to emphasize that the set of stereotypes for each of them is specific. Cultural stereotypes, which arise from the moment when a person begins to realize himself as a part of a certain ethnic group and a certain culture, have a great influence on the regulation of human behavior within the native cultural and linguistic space. It is equally important to note that each language has a special picture of the world, and the linguistic person must organize the content of the statement in accordance with it. The picture of the world of one or another ethnic group becomes the foundation of cultural stereotypes. Her analysis helps to identify differences in the national culture of a particular nation. From this we can conclude that for the successful implementation of the communicative act between different nations, it is necessary not only knowledge of the language, but also the presence of background knowledge, understanding an unfamiliar culture, deciphering "alien" codes and converting them into your own, "natural" ones. Despite the schematism and generalization, stereotypical representations prepare for a meeting with a foreign culture, weakening a possible cultural shock. [8].

Stereotypes are quite stable, but they can change, being affected by changes in the social life of a particular country and the world situation as a whole.

The field of intercultural communication is characterized by the fact that it combines common cultural values with the characteristics of an individual. When communicating with a representative of another culture, information is created taking into account conclusions based on observation plus background knowledge - perception stereotypes that exist until the moment of communication. But since the stereotypes of perception of different cultures can be positive and negative, special attention should be paid to their study and the formation of the right attitude towards them. Competition requires knowledge and understanding of the partner, however, the presence of stereotypes, especially negative ones, often impedes the development of business relations. In this regard, it is important to study stereotypes of perception in order to correct the behavior of partners in various areas of interaction.

So, for the formation of general cultural competencies among students of a technical university in the process of learning a foreign language in a multicultural society, it is 
necessary, firstly, a good knowledge of the culture of the language being studied, and secondly, knowledge of the types of non-verbal communication. The idea of stereotypes and the formation of a correct attitude towards them contributes to the development of intercultural communicative competence, which activates the process of forming general cultural competencies among students of a technical university.

1. Vlasova I.V., Mikhelkevich V.N. The system of development and formation of general cultural competencies among students of a technical university in the process of teaching a foreign language. Bulletin of the Samara State Technical University, a series of "Psychological and Pedagogical Sciences" No. 4 (24) - Samara: SamSTU, 2014.

2. Banartseva A.V., Karpeeva R.S. Stereotypes of perception in the context of intercultural communication. Bulletin of the Samara State Technical University, series "Psychological and Pedagogical Sciences" No. 2 (20) - Samara: SamSTU, 2013.p.30-35.

3. Nesterenko V. M., Ionesov V. I. Man in the system of spatio-temporal relationships: projections and challenges of sociocultural communication. - Bulletin of Samara State Technical University. Series "Psychological and Pedagogical Sciences", No. 2 (20) -2013.-S. 142-148.

4. Karpeeva R.S., Simakova S.M. The formation of intercultural competence in teaching foreign language communication in a multicultural society // University of Culture and Arts in the educational system of the region: Materials of the seventh international electronic scientific and practical conference. - Samara, December, 2009 - February 2010. SGAKI, Part I., p. 260-266.

5. Kurlov A.B. The basics of communication theory. Ufa: RIO of BashSU, 2002.S. 124.

6. Vasilik M.A. The basics of communication theory. M .: Gardariki, 2007.c.617

7. Lippman W. Public Opinion - N.Y; 1950 - p. 95, p. 114.

8. Lanier L.K., Morozova A.N., Dementieva N.Ya., Guseva E.V., Justard D., Kilday K., Klekovkina E.E., Pojyer L.M., Stoykovich G.V. Improve your skills: Textbook on reading and listening to texts based on US culture material. Samara: SamGPU Publishing House, 1997. p.123. 